\title{
Do the conditions in Chinese secondary school education imply a need for global citizenship education? An exploration of six secondary schools in Jiangsu
}

\author{
Yi Hong' ${ }^{1}$
}

Received: 20 February 2020 / Revised: 9 July 2020 / Accepted: 14 July 2020 / Published online: 6 August 2020

(c) Education Research Institute, Seoul National University, Seoul, Korea 2020

\begin{abstract}
Global citizenship education (GCE), an educational advocacy for students to attain the competencies of being aware of and actively engaged in defending social justice, equity and sustainable development at both local and global levels, is difficult to achieve in practice. The failure can be attributed to inadequate knowledge of different effects of GCE when it is used to meet specific needs of local schools. Identifying local schools' needs for GCE may help educators put GCE to good use. However, few studies explore and justify the role of a local insight in assisting in GCE implementation, especially regarding the situation in China where inconsistencies are found across curriculum documents, research and educational practices. The present study fills the gap by investigating the schools' needs for GCE at secondary level within the Chinese education system. With the assistance of principals $(n=6)$ and teachers $(n=10)$ from six participating schools in an anonymous city in Jiangsu province, data were collected through semi-structured interviews and then analysed abductively using the grounded theory approach. Analysis was initially framed by employing criteria from a curriculum development method, namely situational analysis, based on which further analysis was conducted to synthesise more abstract themes. As a result, four general conditions emerged from the data, including three restrictive conditions that may prevent GCE integration (i.e. 'compliance and commitment', 'social mobility' and 'administrative constraints') and one condition that can encourage GCE implementation (i.e. 'competency-based education'). Since GCE is a complex idea linked to many possible applications, the four key conditions revealed from the small sample in the present study can enrich researchers' understanding of the potentiality of GCE implementation in similar moderately developed cities on the east coast of China.
\end{abstract}

Keywords Global citizenship education · Chinese secondary schools $\cdot$ Situational analysis $\cdot$ Curriculum studies $\cdot$ Grounded theory $\cdot$ Identity building

\section{Introduction}

Today, regardless of their nationality, globalisation affects people in more comprehensive ways than it did a decade ago. While globalisation was arguably more focused on the macro domains of economics, mobility and multilateral cooperation, in recent years it has been associated with a more profound influence on citizens' daily life through ideologies and values, such as post-truth politics, due to the rise of

Yi Hong

yhon8199@uni.sydney.edu.au

1 The Sydney School of Education and Social Work, The University of Sydney, A36 Education Building, Camperdown, Australia online media (Braun 2019), and lifestyle, such as the new way of living in the Anthropocene (United Nations Educational, Scientific and Cultural Organisation [UNESCO] Courier 2018).

The current development of globalisation is related to structural and institutional changes, for example, the erosion of the traditional political framework by neoliberalism (England and Ward 2007); however, it is more likely that nowadays, globalisation reflects the developmental paradigm of political science in academia where the individual perspective is weighed and prioritised as the key factor in agency-led democracy (Torney-Purta 2002, p. 203; Youniss et al. 1997, p. 620). This developmental paradigm has been valued and applied by scholars as the basis for identifying the role of education, a vital part of political socialisation, in predicting the democracy of their domestic politics in 
the future (Hyman 1959; Jennings 2007; Settle et al. 2011; Torney-Purta et al. 2004). This paradigm has also been used to explain the role of education in affecting the societal order of the world. Since the early 2000s, the term global citizenship education (GCE) has been discussed, though mainly at the theoretical level (Banks 2008; Davies 2006; Nussbaum 2002; Print 2015; Tye 2003). In this study, I address GCE as education that enables people to attain the competencies of being aware of and actively engaged in defending social justice, equity and sustainable development at both local and global levels (Oxfam 2015).

Many studies highlight that GCE may have more complex multidimensional meanings than the definition provided above. Via iterative analysis of extensive English-based academic works, Oxley and Morris (2013) identified the demarcation between the cosmopolitan type and the advocacy type of GCE. The cosmopolitan type of GCE emphasises creating a universal identity underpinned by the transcendent morality and humanity. The essence of cosmopolitanism, which can be traced back to ancient civilisation, has been integrated into educational traditions across countries. For instance, Dill (2013, p.135) found that when constructing GCE pedagogies based on the "cosmopolitan thriving and its particular self" (i.e. he vision of the individual and society in a human flourishing condition and the imagination of an expressive and utilitarian self), American educators' global imagination is dependent upon their historical and cultural circumstances. However, the cosmopolitan type of GCE is criticised for several limitations and it is suggested that the advocacy type of GCE should replace it. Andreotti (2006), who also divides approaches to GCE into cosmopolitan and advocacy types (despite using the terms 'soft' and 'critical' as the alternatives, respectively), argues that the cosmopolitan approach only uncovers the analysis of the benefits and downsides, while the advocacy approach dissects problems systematically. Gaudelli (2009) frames cosmopolitanism as a concept featuring the 'imaginary' and 'cooperative' aspects of GCE when juxtaposing it with more tangible ideas, such as world justice. Similarly, Davies (2006) foresees the risk of mistaking GCE as an oxymoron when interpreting it merely as an identity arching over the national identity. By analysing past attempts (e.g. documents, curricula and programmes) to construct GCE, she concludes that GCE should be on developing active citizens who contribute to social justice, rights, and engagement with culture as well as cultural conflicts. It is even inferred that the advocacy type of GCE can achieve the learning outcomes of the cosmopolitan type of GCE in addition to achieving its own, as Nussbaum (2002) suggests that the sense of belongingness and narrative imagination of a cosmopolitan society can be achieved along with critical self-reflection through liberal education.

Moreover, the advocacy-oriented theorisation of GCE is validated in several empirical studies. Findings in some negative cases, including South Korea (Cho and Mosselson 2018), Japan (Hammond and Keating 2018) and Ghana (Howard et al. 2018), suggest that to achieve the designed GCE outcomes, social justice and equity cannot be avoided as otherwise, reverse outcomes of reinforced neoliberalism and post-colonialism will be caused.

In addition, feedback from the local practices can help to refine the specific educational need to implement GCE, which extends the advocacy suggested in the theoretical constructs. According to a report by UNESCO (2015), GCE has been accepted as part of the curriculum objectives in Australia, Colombia, Indonesia, South Korea, Tunisia and England and translated in several examples in the non-formal curriculum in countries through programmes such as Activate South Africa and Peace First in Colombia and the United States. The variation in curricular arrangements reflects how the need for GCE is different across contexts and sheds light on the need for adding knowledge of local conditions to the GCE research.

It is evident that the nature and implementation of GCE in different contexts requires ongoing investigation. There is a research gap regarding the mismatch between GCE's functions and the local needs, which results in many unsuccessful attempts to implement it (see subsection 'Global citizenship education and the relevant practices'). In this study, I will focus on exploring the schools' need for GCE in the Chinese context, where there is a lack of discussion on GCE, and relevant policies, local research and curriculum practices of GCE conflict with each other. China is an active member of UNESCO; however, there were no records related to the situation of GCE in China in UNESCO's report (UNESCO 2015). As a place where education affects citizens through their ways to cope with the increasing freedom of mobility, communication and economic conditions (Featherstone 2002; Podoshen et al. 2011), the Chinese case merits attention. After reviewing academic literature that focuses on the Chinese case, several explanations were found for the negligence of GCE, including the goal of educating 'people' rather than 'citizens' (Zhao 2010), the emphasis on patriotism and nationalism in Moral Education ( $\mathrm{Li}$ 2003), the priority of national citizenship learning (Wang 2019), the government's advocating of socialist-oriented citizenship and oppression of globalist views (Law 2006), the choice of promoting a type of anti-feudal Moral Education under the influence of the New Culture Movement (Wang 2016), and the long-lasting impact of political hegemony in Chinese people's discourse (Gow 2017). It seems that the advocacy type of GCE has not been fully explored at the theoretical level because of the institutional restrictions imposed on academics. However, a more comprehensive understanding regarding whether Chinese schools imply a need for GCE may be achieved if knowledge of local conditions is added. 
Using six secondary schools in China as an example, I aimed to explore to what extent the Chinese secondary schools need GCE to improve students' political socialisation and prepare them for changes in globalisation. In this study, because of the complexities of the contextual impact, unless it was requested, existing theoretical models were not introduced to the school personnel during the data collection. A concise definition adapted from Oxfam (2015) ${ }^{1}$ was provided for participants' reference (i.e. the definition of GCE stated above) to initiate their reflections on whether their schools need GCE with their own justification. Inevitably, there was variation in participants' conceptions of GCE (a common phenomenon in curriculum development due to the research-practice gap; continuous 'trial and error' will be encouraged to achieve success [Teasdale 1997]), whereas their perceptions of justifying the need for GCE in their schools revealed consistent patterns. At the end of this paper, I will suggest that GCE was not easily accepted and integrated into the participating Chinese schools in the same way as it has been in other countries but was implemented through more subtle competency-based education. The study results relate to educators' predictive indicators of the prevalence of GCE in secondary schools on the east coast of China that have similar conditions. The approach to investigate GCE from educators' perspectives provides a way to generate knowledge of GCE as a systematic construct of local schools' conditions rather than only being responsive to external factors associated with school education.

\section{Global citizenship education and the relevant practices}

Our understanding of GCE began with theoretical explorations, which included offering literal meanings by interpreting semantic components of GCE (Davies 2006, pp. 13-14), translating the meaning of GCE into ideologies (Gaudelli 2009; Oxley and Morris 2013) and associating it with other types of education, such as global education, development education, peace education, international education and multicultural education (Hicks and Townley 1982; Reynolds 2015). Transferring a less developed concept such as GCE across contexts is substantiated by relevant educational functions, evidenced by both successful and ineffective cases, in the empirical settings. The process of operationalising GCE, compressing the highly abstract idea into implementation with targeted educational functions, is widely seen

\footnotetext{
1 "[Although] an expanding population has become global citizens passively as [a] result of the neoliberalised job market, wars, financial crisis, or technology advancement (i.e. netizens), Oxfam's definition contributes to an important opinion that global citizenship is a status for people to attain rather than [being] conferred naturally or passively" (Hong 2019, p. 2).
}

across different countries (Abdi 2008; Banks 2008; Ho 2009; McKinney 2008; Niens and Reilly 2012; Print 2015; Tarozzi and Torres 2016; Zhou 2011). The review of the literature revealed several educational functions of GCE, for example, extending civic education by offering a global perspective (Davies 2006; Print 2015; UNESCO Asia-Pacific Centre of Education for International Understanding 2019), assisting immigration integration (Banks 2008; Tarozzi and Torres 2016; Zhou 2011), solving religious conflicts (McKinney 2008; Niens and Reilly 2012), and resolving historical issues (Abdi 2008; Ho 2009).

Moreover, these different educational functions reveal regional patterns, and such pattern is consistent with the need for preserving heterogeneity in identity building in many curriculum studies. For instance, in curriculum studies, preserving heterogeneity is needed to prevent curriculum practices from being assimilated by the global hegemonizing knowledge in the process of economic globalisation (Koh 2007; Lingam et al. 2014). Adopting this perspective, it is possible to attribute some ineffective cases of practising GCE to the failure of addressing the need for maintaining the independence of culture in economic globalisation. For instance, practices reveal that the tendency of inheriting the Western-centric common grounds for interpreting GCE reproduces the imbalance between the Global North and the Global South, West and East, and between developed and developing countries. In a study investigating how schools fulfil their commitment to GCE (since it has become an agenda in the national curriculum for promoting social justice), it is found that influenced by Korea's Confucian collectivist cultural heritage, the imbalanced rhetoric about the international positions between some Western countries and some non-Western countries caused reproduction of neoliberal hegemonies and inequality (Cho and Mosselson 2018). In Japan, however, another developed Asian country, a case study found that GCE has been adapted in a way that follows neoliberal objectives targeting employability with a strengthened notion of ethnic identity (Hammond and Keating 2018).

Moreover, as suggested in curriculum studies, the need for preserving heterogeneity can be classified into preserving the heterogeneity of many marginalised local cultures in regionalised curriculum development and preserving the heterogeneity of the nation-state citizenship solely within the curriculum of developing legitimising identity. On one hand, in regions where the local culture is marginalised, a regionalised identity is needed to maintain the heterogeneity of many marginalised local cultures (Koh 2007; Law 2002; Thaman 2009). This is applicable to sub-Saharan Africa, where GCE is understood as an approach for empowering people in an anti-oppressive perspective to resolve the influence of the de-citizenising scheme during the colonial period (Abdi 2008). It has been shown that cases where the 
heterogeneity in regional identity is missing usually encounter difficulties in achieving the desired effects. For instance, a study found that in a Ghanaian secondary school, where GCE has been integrated into the curriculum to uphold the mission of developing native intelligence, the elite school context fails to enable students to realise that the African history, culture and language are highly diversified and fluid but reinscribes an underprivileged and homogeneous concept of Africa. Consequently, these elite students become more willing to pursue a future in the West (Howard et al. 2018).

On the other hand, in regions where the dominant culture is highly heterogeneous, the focus should be on fostering the nation-state citizenship to balance tensions in civil society, such as advocating the indigenous right rather than equity (Teasdale 1997). This is applicable to places where GCE has been acknowledged in the political rhetoric for solving immigration integration. Examples of this are found in the United States, with multicultural education focusing on helping students to find a balance among cultural, national and global identities, with a strong inclination towards nationalism (Banks 2008; Tarozzi and Torres 2016; Zhou 2011), and in the Anglo-Saxon world and Northern Europe, where it has been acknowledged that intercultural education can alter the situations of migrant populations and marginalised ethnicities (Tarozzi and Torres 2016). In addition to including GCE in the curriculum as an effective element in achieving a balance between the extremes of ethnocentrism and relativism, it is suggested that GCE can be used to ameliorate the problem of maintaining historical issues of racial riots in Singapore (Ho 2009). Moreover, it is applicable to areas that need to solve religious conflicts, such as those in Northern Ireland and Scotland, where it has been suggested that GCE can be used as an approach for smoothing sectarian conflicts within Christianity (McKinney 2008; Niens and Reilly 2012).

It should be noted, however, that cases where the heterogeneity of the legitimising identity is not fully emphasised also encounter problems. In Australia, although GCE is linked through the cross-curriculum priorities and general capabilities, it is marginalised and difficult to maintain among schools with increasingly challenging domestic and international contexts (Buchanan et al. 2018; Print and Buchanan 2019). In teacher education in the United Kingdom, GCE is second to and conflicts with the obligation of promoting fundamental British values (FBV), as a result of which, teachers display different attitudes (i.e. comfort, compliance, criticality, and critical being) towards GCE and FBV (Bamber et al. 2018). Furthermore, in conflict-ridden societies, defined by UNESCO $(2015$, p. 9$)$ as places where 'there may be particular political, social and/or cultural sensitivities', meanings of GCE have been expanded and changed in the service of various interest groups. For example, in Israel, the specific context of an ethnic democracy (meaning 'the major ethnic or religious group uses state structures and resources to maintain its interests'), there is no policy on GCE, with teachers understanding GCE as part of the state and relevant institutional interests (Goren and Yemini 2016). In a study conducted in South Sudan, a country that was not established until 2011, the post-conflict context makes it difficult to implement not only GCE, but also the education for national citizenship, even with the available curriculum framework addressing the concept of global citizenship (Skårås et al. 2019).

With assistance from Castells' (2004) framework on identity building ${ }^{2}$, the reviewed literature reveals that these two approaches, preserving heterogeneity through regionalisation and through citizenship education, respectively correspond to approaches to building a resistance identity, meaning an identity opposing a dominant identity (discussed beyond the state border), and a legitimising identity, meaning an identity for becoming a social actor in civil society (discussed within the country).

The desired degree of heterogeneity of the sociocultural environment where the schools are situated is likely to influence how successful GCE will be in schools. As implied by Teasdale (1997) based on empirical evidence in curriculum studies across seven major countries in the Asia-Pacific region, it is possible to develop successful plans for promoting the varied facets of identities through long-term curriculum construction. In other words, the level of heterogeneity (reflected in either legitimising identity or resistance identity, or both) is measurable through systematic evaluation during curriculum development. The level of heterogeneity manifests as learning conditions in the curricula (formal, informal and extracurricular activities), which are suggested as avenues of political socialisation (Print 2007) and an institutional basis to preserve heterogeneity when the school associates with other social sectors, including family, community and non-governmental organisations (NGOs) (Geboers et al. 2013; Print 2007).

\section{The case of Chinese secondary schools}

This section will build on the concepts introduced previously in the Chinese case (i.e. GCE as an approach for preserving heterogeneity in legitimising identity and resistance identity building). First, the background information of the Chinese case will be discussed. Subsequently, the focus will be on

\footnotetext{
2 In Castells' (2004) theory, in addition to building the legitimising identity and the resistance identity, there is discussion on developing a more subtle identity, namely the project identity. This identity relates to an incommensurable psychological condition to drive people to transform themselves to obtain the resistance identity. In this study, I prefer not to elaborate on the project identity as it is less relevant to the possible changes in school curriculum development.
} 
examining the consistency among curriculum documents, local research and educational practices. Specifically, the evidence of heterogeneity in legitimising identity building and resistance identity building will be evaluated. This section aims to generate an authentic context regarding the GCE in China.

The Chinese education system consists of basic education (1-6 year in primary schools, and 7-9 year in secondary schools, both of which are mandatory), high school education (10-12 year), tertiary education, and vocational education. The system is famous for producing high-performing students and notorious for creating toxic levels of academic stress (Zhao et al. 2015). I believe it is important to investigate the GCE in secondary schools in China since these schools, which are already experiencing globalisation, need to implement GCE to improve the quality of education for their increasingly aware students. Chinese students are reported to be more mobile as for seeking educational opportunities (the number reached 662,100 in 2018 [National Bureau of Statistics of China 2019]) and traveling abroad (71.3 million overseas visits were made in the first half of 2018, which included many secondary school students [iiMedia Research 2019]), given that their country has a fast-growing economy (Kennedy 2014; Xu 1998) with $72 \%$ of the population will be middle class by 2030 (Kharas 2011, p. 13, p. 15).

Intensified by the sudden economic and demographic transformations, the situations local schools confront in this increasingly globalised country might echo what Dill (2013) describes as a condition full of complexities and uncertainties, as well as anxieties and hopes. Subtle responses to cope with globalisation have been revealed, though doubts remain regarding whether these responses are closely linked with GCE's function of preserving heterogeneity in identity building. To support this, curriculum documents, local research and educational practices will be discussed in the rest of this section.

First, by being related to GCE, some key curriculum documents lack precision regarding approaches for preserving heterogeneity in identity building since a variety of conflicting ideologies are listed while little guidance is given for their implementation. For instance, a theoretical framework was published in 2016 after a three-year research study was conducted by scholars from Beijing Normal University and other universities. This framework explicates the overarching idea of all-round development of human beings in curriculum practices, including self-development, civic participation and cultural infrastructure (Fig. 1; Core Competencies Research Group 2016). As the advocacy elements have been limited to 'learn to study', 'practice innovation' and 'scientific mindset', this document provides a negative stance regarding inclusion of the heterogeneity related to foreign influences.
- $\quad$ Self-development

Learn to study; lead a healthy life

- $\quad$ Civic participation Being responsible; practicing innovation

- Cultural infrastructure Cultural heritage; scientific mindset

Fig. 1 Theoretical framework of developing "the all-around development of human beings" by the Core Competencies Research Group (2016)

Moreover, many ideas pertaining to national and international values present in the current national curriculum standards (Moral Education) under the categories of 'values and dispositions', 'skills' and 'knowledge' contain a mix of propositions (Ministry of Education 2011). For 'values and dispositions', there are components requiring students to develop socialism, Chinese culture and a global perspective, while for 'skills', the learning goals are emotion control, communication skills and media literacy, which emphasises qualities described in the literature as being a disciplined, having social awareness but autonomous citizen (Johnson and Morris 2010; Print 2013; Veugelers 2007; Westheimer and Kahne 2004). For 'knowledge', the curriculum goals primarily concern understanding the world through a nationalist perspective. More evidence is manifest in the section 'curriculum contents', where curricular goals are amplified as basic communication skills (statement 2.6 in 'curriculum contents'), multiculturalism (statement 2.7 in 'curriculum contents' and statement 2.7 in 'activity suggestions'), nationalism (statement 2.8 in 'curriculum contents') and cosmopolitanism/moral imagination of the world (statement 2.7 in 'curriculum contents' and statement 2.7 in 'activity suggestions'). It is therefore summarised in this study that ideas in the national curriculum standards imply the passive response to the ideological changes in globalisation without a clear indication of preserving heterogeneity at the crossnational level.

Moreover, there is inconsistency between the curriculum and policy documents and Chinese scholars' arguments related to the theorisation of GCE. For instance, Peng (2009) suggests adopting cultural nationalism as the basis for introducing GCE but emphasises Confucianism and therefore promotes ethnic nationalism rather than cultural nationalism. Song and Rao (2018) suggest developing the global perspectives based on socialist nationalism without highlighting the essential competencies, such as activism, for promoting the social equality aspect of socialist nationalism. Li (2009) proposes that GCE is an approach to participate in civil society not only within the country, but also at the international level, which coincides with the citizenship paradigm suggested in Republican China's synthesis 
approach (Law 2013). Although these arguments in the local literature are narrated to favour a similar cosmopolitanism orientation (Wang 2019), the ideologies that underpin these arguments conflict with each other (e.g. socialist nationalism rejects ethno-nationalism, and neither socialist nationalism nor ethno-nationalism favours the multiculturalism orientation in the current national curriculum [see statement 2.7 in 'curriculum contents']) and are close to the theoretical basis of the advocacy type of GCE. More importantly, since these local theories on GCE conflict with each other, there is no consensus on how to preserve the heterogeneity in identity building.

In addition to the inconsistency between curriculum documents and research related to GCE, there is empirical evidence from schools indicating an unexplored gap of GCE-related practices. Although Shi et al. (2019) claim that it was less common for GCE-related goals and contents to be implemented with an immersion approach in schools in mainland China, meaning that GCE was not addressed as extensively in other formal subjects as it was in Hong Kong schools, secondary schools in mainland China rely heavily on outsourcing resources for the immersion approach (Hong 2019). This strategy of using outsourcing resources is shown through some activities implemented in parallel to the authorised subject of Moral Education in participating schools, fortified by various NGOs, foreign institutions and grassroots groups. For example, the Model Chinese People's Political Consultative Conference programme is promoted by the China Zhi Gong Party, one of the United Front Democratic Parties that consists of Chinese students who have returned from overseas. Moreover, the Model United Nations programme has been supported by the Australian Human Rights Commission as part of the China-Australia Human Rights Technical Cooperation Programme since 1999.

The purpose of the collaboration with agents outside schools is to fulfil the 'Core Competencies and Values for Chinese Students' (Core Competencies Research Group 2016) through the opportunity to develop a school-based curriculum, called the Integrated Practical Activity Curriculum (IPAC), implemented by the central government since 2001 to give autonomy and power to Chinese secondary schools. However, the IPAC inevitably functions as an empty shell with many problems, for example, the instructional guidelines are vague regarding accessible resources for students to design their projects, guidelines lack coherence and precision, supplementary documents were not being constantly updated and many of them had overlapping instructions, and there is a lack of well-developed curriculum resources (Zhang 2006, p. 69; Zheng 2008, pp. 83-84). It has also been reported that during the implementation stage, both teachers and students experience confusion in the project-based learning context of the IPAC as it differs from the traditional didactic teaching, which requires students and teachers to know the intention of the project or what a learner-based curriculum should be like, while teachers show little motivation to engage in supervising projects (Zhang 2006; Zheng 2008).

Furthermore, in some extracurricular activities exclusive to a small number of students, it is highlighted that Chinese schools have a strong inclination towards a global perspective but away from civic content. For instance, Law (2014) and Pan (2014) found that international events (e.g. the Beijing Olympic Games and the World Exposition in Shanghai), though proven to be useful channels for promoting multidimensional citizenship education, do not offer opportunities for training active citizenship-related knowledge and skills. Likewise, it was the multiple citizenship perspective in the 'Beijing Consensus on Citizenship Education' or the communication competence and international outlook due to Chinese students' enthusiasm for learning English (Chen 2014 , p. 155) that might convince outsiders of the relevance of these educational activities to GCE, despite none of them including the advocacy aspect of GCE.

As seen in this section, the Chinese context of GCE is highly contested as the curriculum lacks precision on GCE, scholars' theoretical explorations of GCE conflict, and empirical evidence in schools remains largely unexposed. Therefore, I argue that there is a need to explore the Chinese case by collecting empirical evidence of the conditions within local schools. Following a perspective in curriculum studies, such as using Print's theory (1993) in the study investigating educators' views on evaluating foreign ideas in local schools (Lingam et al. 2014), I adopted curriculum development theory as a theoretical framework for guiding an investigation into the current situation of GCE in Chinese secondary schools. I used situational analysis, an initial stage of the curriculum development, to obtain educators' preliminary thoughts on the possible need for GCE in their schools.

\section{Theoretical framework}

The present study adopted Skilbeck's situational analysis (Table 1) suggested in Print's theory (1993) to frame the extent of the need for GCE. Situational analysis, adapted from a curriculum development model, seeks an explanation of what GCE is and how it is implemented in secondary schools. The design of the present study relies on the idea that situational analysis is key to gain knowledge of the context where a curriculum is going to be developed or be consolidated in a new premise, which is a result of the diagnosis of the local needs reflected through the complicated interplay among various factors (Print 1993, pp. 109-111).

Print (1993) reviewed and refined the major curriculum development theories and identified a model of curriculum development comprising phases of organisation, 
Table 1 A modified table based on "Factors in Situational Analysis" (Print 1993, p. 115)

\begin{tabular}{|c|c|c|c|}
\hline \multirow{2}{*}{$\begin{array}{l}\text { External factors to the school } \\
\text { Cultural and social changes and expecta- } \\
\text { tions }\end{array}$} & \multirow[b]{2}{*}{$\begin{array}{l}\text { Unemployment patterns } \\
\text { Societal values } \\
\text { Economic growth } \\
\text { Family relationships }\end{array}$} & \multicolumn{2}{|c|}{ Internal factors to the school } \\
\hline & & Pupils & $\begin{array}{l}\text { Ability } \\
\text { Physical and psychological development } \\
\text { Aptitudes } \\
\text { Emotional and social development } \\
\text { Educational needs }\end{array}$ \\
\hline $\begin{array}{l}\text { Educational system requirements and chal- } \\
\text { lenges }\end{array}$ & $\begin{array}{l}\text { Policy requirements } \\
\text { Inquiry reports } \\
\text { External examinations } \\
\text { Major curriculum projects } \\
\text { Significant educational research }\end{array}$ & Teachers & $\begin{array}{l}\text { Skills } \\
\text { Experience } \\
\text { Teaching style } \\
\text { Values } \\
\text { Special strengths and weakness }\end{array}$ \\
\hline Changing nature of content & $\begin{array}{l}\text { New knowledge } \\
\text { Technological development } \\
\text { New literature }\end{array}$ & School ethos & $\begin{array}{l}\text { Principal involvement } \\
\text { Power distribution } \\
\text { Social cohesiveness } \\
\text { Operational procedure } \\
\text { Professional cohesiveness }\end{array}$ \\
\hline Teacher support systems & $\begin{array}{l}\text { Tertiary consultants } \\
\text { Advisory teachers } \\
\text { In-service courses } \\
\text { Subject associations }\end{array}$ & Perceived problems & $\begin{array}{l}\text { Needs from parents, teachers, students and } \\
\text { community }\end{array}$ \\
\hline Resources & $\begin{array}{l}\text { Resources from Commonwealth } \\
\text { sources } \\
\text { Resources from state education } \\
\text { departments } \\
\text { Resources from the community } \\
\text { and business organizations }\end{array}$ & Material resources & $\begin{array}{l}\text { Buildings, land and vehicles } \\
\text { Equipment } \\
\text { Resources (books, facilitates curriculum } \\
\text { materials) } \\
\text { Financial resources for future purchase } \\
\text { Knowledge of resources facilitates cur- } \\
\text { riculum planning }\end{array}$ \\
\hline
\end{tabular}

development and application. These phases involved situational analysis; aims, goals and objectives; content; learning activities; and instructional evaluation. According to Print (1993), "As the situation changes with time (due to changed societal circumstances, different types of students, new technology, additional content information, and so forth) so the monitoring of the curriculum should report the direction for needed changes" (p. 219).

Situational analysis is a key step of curriculum development that can explain how the curriculum is likely to be developed to adjust to situation changes. For this study, it underpins the investigation of how educators evaluate the need for GCE in participating schools. By investigating the 'cultural and social changes and expectations', 'educational system requirements and challenges', 'changing nature of content', 'teacher support systems' and 'resources', an understanding can be gained of the degree of heterogeneity in the curriculum composition in participating schools. Moreover, situational analysis invites curriculum developers, the principals and teachers in the present study, to evaluate the conditions of their schools to determine the likelihood of the success of GCE. By exploring the 'pupils', 'teachers', 'school ethos' and 'material resources', it is possible to understand manpower's acceptance of acting on the idea of GCE as preserving heterogeneity in identity building.

\section{Methodology}

The present study is a form of qualitative research that employed the post-positivist grounded theory (Charmaz $2006,2011)$ to support the production of middle-range theory. The post-positivist grounded theory is applied to data collection and analysis within boundaries (e.g. pre-existing coding and analytic framework) yet is open to adapting or changing conditions by expanding these boundaries (Charmaz 2006, 2011). The capability of examining conditions both within boundaries and expanded boundaries (i.e. abductive logic) has advantages in exploring the unknown conditions of the curriculum for preserving heterogeneity in identity building to understand how likely it is that there would be a need for GCE in schools in this Chinese case.

Between September and November 2017, principals $(n=6)$ and teachers $(n=10)$ from six secondary schools in an anonymous, moderately developed city in Jiangsu province, China, were purposively sampled to formulate a representative case (Table 2 ). I chose this city because the examination results statistics in this place were often used by local educators as the average conditions on the east coast of China (Hong 2019, p. 4). For data collection, face-to-face semi-structured interviews were arranged for the participants based on instruments adapted from a study (Lee and Leung 2006) examining GCE in Hong Kong and 
Table 2 Characteristics of the six schools in the present study (based on interview data)

\begin{tabular}{|c|c|c|c|c|c|c|}
\hline School & $\mathrm{HY}$ & QY & $\mathrm{CW}$ & $\mathrm{CZ}$ & $\mathrm{CY}$ & $\mathrm{FL}$ \\
\hline Educational sector & Government & Government & Independent & Government & Government & Government \\
\hline Location & Mid-distant suburb & Inner-city suburb & Suburban fringe & Mid-distant suburb & Inner-city suburb & Suburban fringe \\
\hline Established & 1981 & $\begin{array}{l}\text { Reconstituted in } \\
2002\end{array}$ & 2001 & 1997 & 1950 & 2014 \\
\hline School size & Small & Moderate & Huge & Moderate & Small & large \\
\hline Student gender & Coeducational & Coeducational & Coeducational & Coeducational & Coeducational & Coeducational \\
\hline Student background & Low-SES & Moderate SES & High SES & Moderate SES & Low-SES & Low-SES \\
\hline School ability type & Comprehensive & Comprehensive & Selective & Comprehensive & Comprehensive & Comprehensive \\
\hline $\begin{array}{l}\text { Modal student } \\
\text { performance }\end{array}$ & Moderate & Moderate-high & High-academic & Moderate-high & Moderate & Low-moderate \\
\hline $\begin{array}{l}\text { Key GCE related } \\
\text { activity }\end{array}$ & Project citizen & IPAC & $\begin{array}{l}\text { Project-based } \\
\text { learning }\end{array}$ & IPAC & Thematic activities & Project citizen \\
\hline
\end{tabular}

Table 3 Participants in the present study (based on interview data)

\begin{tabular}{lllllll}
\hline Schools & HY & QY & CW & CZ & CY & FL \\
\hline Principals & Principal B & Principal U & Principal C & Principal W & Principal Y & Principal Z \\
Teachers $^{\mathrm{a}}{ }^{2}$ & Teacher A & Teacher W & Teacher J & Teacher L & Teacher H & Teacher F \\
& (Junior, ME) & (Junior; ME) & (Junior; ME) & (Senior; ME) & (Senior; ME) & (Senior; ME) \\
& Teacher T & & & Teacher Z & Teacher C & Teacher M \\
& (Junior; MH) & & & (Senior; ME) & (Senior; ME) & (Junior, ME) \\
\hline
\end{tabular}

${ }^{a} J u n i o r$ within three years of teaching; senior more than three years of teaching; $M E$ moral education subject; $M H$ mental health

Shanghai secondary schools (Appendix 1). The principal was the first interviewee of every school. Principals were encouraged to nominate at least two teachers to participate in face-to-face interviews. In total, six principals and ten teachers participated in the interviews (Table 3). Since the unit of analysis was the school, the different number of participants in each school did not significantly influence the results. Ethical approval for the data collection procedure was obtained from the Human Research Ethics Committee of a major Australian university.

For each interview, two audio recorders were employed simultaneously to ensure the quality and integrity of the recordings. Subsequently, interviews were transcribed without being translated into English. The transcripts were analysed by NVivo 11 in Chinese following the stages of conceptualisation, coding, memo writing and outcropping (Neuman et al. 2014, pp. 480-487).

In the grounded theory analysis, a group of potential factors (Table 1) that influenced the integration of GCE in six Chinese secondary schools were used for sorting evidence, which comprised teachers' and principals' answers in the interviews. Systematic analysis of the dense information, framed by the situational factors, generated a list of 13 more abstract themes. These 13 themes supported the generation of the macro-themes providing key information about the context-specific GCE in participating schools.
Subsequently, based on the inductive reasoning of these 13 themes, four major themes were identified as the essential conditions for the participating schools: the culture of compliance and commitment, the schooling purpose of maintaining social mobility, the goal of providing competency-based education and administrative constraints (Fig. 2). Finally, the analysis proceeded by integrating these four major themes with existing knowledge in the literature and synthesising the general pattern concerning the conditions for integrating GCE into Chinese secondary school education.

\section{Compliance and commitment}

The first finding is that participants' responses confirmed the descriptions of the peculiarities of the Chinese context in that the schools are located within a system where the professional disciplines prioritise efficiency. Evidence for this was drawn from the themes revealed by the internal factors of 'teachers' and 'school ethos'.

Information about the teacher factors revealed that they possessed highly consistent professional skills and mindsets. This level of consistency results from complying with consistent training and work requirements and leads to teachers' commitment to similar values and teaching outputs. Regarding the teaching of the formal curriculum, these teachers have similar characteristics in terms of their values, which 


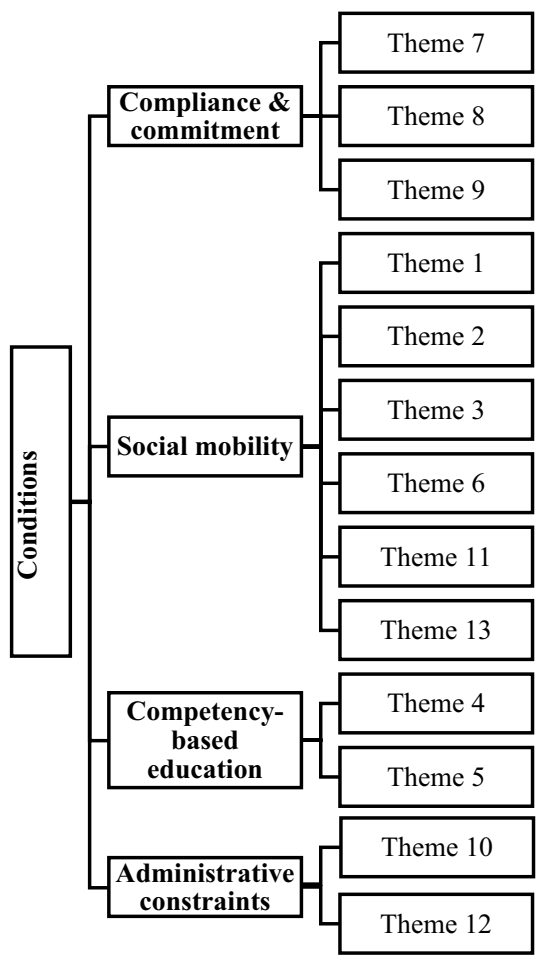

Fig. 2 Four major themes emerged from 13 themes generated from the data of the present study

seem to be shaped by their educational background and the training they have received.

Moreover, the teachers showed a strong sense of commitment to the subject they were teaching. This was consistent with their teacher education training during their undergraduate years regardless of the school where they worked. They frequently used phrases and sentences from the textbooks to answer the interview questions. In addition to the education for undergraduate degrees, professional training opportunities were provided by the local educational bureau, through which teachers can improve their professional skills at a consistent pace and in a uniform manner, thereby reinforcing their teaching commitment to authoritative standards/ norms. Despite the consistent training, the consistency in values shared among teachers resulted from their similar work experience, including their experiences of being headteachers and of teaching Moral Education.

However, the compliance and commitment in teaching was mainly manifest in delivering the formal curriculum subject (Moral Education) rather than in experience related to the informal curriculum. When I was collecting data in CZ secondary school, Teacher Z informed me that when she was involved in an outsourcing project-based learning programme called Project Citizen, which was part of the IPAC, she and her colleagues used an apprenticeship-like mentoring strategy to train junior teachers as there was no unified training for teachers to become supervisors in project-based learning. Moreover, Teacher $\mathrm{Z}$ admitted that since people worked in mentor-mentee pairs, they did not have many opportunities to exchange ideas; consequently, everybody ended up creating their own understanding, experience, techniques and styles to fulfil the supervisory role in the informal curriculum.

Teacher Z's comments on the diversity in supervising concurred with the varied signs of progress in implementing the informal curriculum in other participating schools. It was found in HY secondary school that teachers conducted supervision with a focus on project management, such as by preparing project topics, offering exemplars, and training students in predicting realistic project outputs. Conversely, in QY secondary school, as teachers had the impression that students were too junior to complete projects independently, they adopted students' roles in working out the theoretical framework, step-by-step instructions, data management and data analysis. As found in these instances, whether positive or negative, teachers' responses within the informal curriculum were already different from any standardised learning objectives in the formal curriculum. A more worthwhile pattern revealed that because of different expectations of the roles in the informal curriculum, teachers started to follow a learning curve for their own civics-related knowledge, values and visions. It was also found that participants who made similar comments were more likely to be from schools where more attention was paid to the informal curriculum, and therefore greater individuality and independence from the strictures of the formal curriculum were allowed.

In a less evident way, compliance and commitment were manifest in participating schools' operational procedures, especially the curriculum arrangement. It was rarely possible to include additional tasks in these schools' curricula regardless of how intense the requirement to make adjustments based on schools' needs might be. This common feature was categorised as an overcrowded curriculum in interpreting the school ethos (Print 1993, pp. 151-152). During interviews, participants were less enthusiastic about the idea of undertaking additional tasks related to GCE in their schools. For instance, Principal Z (FL) admitted that the main work of the Moral Education course is not GCE but delivering the specific Moral Education curriculum. In other words, GCE would be an additional duty for teachers and principals.

Finally, the less democratic work environment in participating schools might also reinforce the theme of compliance and commitment. It was difficult for schools to ease the tensions caused by assessment and evaluation. Most teachers stated in the interviews that the best way to implement GCE would be to include it within the examination system, as otherwise it would be challenging for schools to develop GCE by themselves since it was perceived as being of less 
Table 4 The selected factors and the themes generated from the data of the present study

\begin{tabular}{ll}
\hline Selective factors from the list of factors in situational analysis & Themes \\
\hline Cultural and social changes and expectations & Theme 1: lack of capital resources \\
& Theme 2: need more supports from parents \\
Educational system requirements and challenges & Theme 3: lack support from communities \\
Changing nature of content & Theme 4: criticisms of drawbacks of the traditional score- \\
Pupils & based education system \\
Teachers & Theme 5: quality of education \\
School ethos & Theme 6: purpose of schooling \\
& Theme 7: highly consistent professional skills and mindsets \\
& Theme 8: the overcrowded curriculum \\
Material resources & Theme 9: less democratic work environment \\
\hline
\end{tabular}

value given that it was not assessed in schools. This was a typical response from a participant:

Basically, all the activities were organised by the school. The decisions about organising particular activities and courses are made by hierarchies of the education system, level by level. And there have been really, really too many such activities. Therefore, we seldom plan activities or courses by ourselves. What we have been occupied with is completing tasks. (Teacher W, QY).

\section{Social mobility}

The findings on schools' conditions related to the schooling purpose. In the present study, social mobility (Fig. 2) was the second concern identified by the analysis (Table 4). The term 'social mobility' was envisaged by Labaree (1999) as one of the three schooling models for explaining school effectiveness. The social mobility function refers to an evaluative understanding of schooling as an approach to attain the goal of training students to be competitive and prepared for obtaining and securing jobs after graduation, as well as a normative strategy of measuring knowledge via grades and credentials (Macbeath 2004, p. 25). It was in relation to the nature of social mobility that participants expressed their concern about maintaining and improving school effectiveness when considering the general context of schools.

By reflecting on the external factor of 'cultural and social changes and expectations', it was found that even though the need to cope with globalisation was widely acknowledged across schools, participants gave conflicting responses to the notion of social capital, a key resource for supporting school effectiveness (Macbeath 2004, p. 28;
Print and Coleman 2003). In other words, although participants confirmed the need to implement GCE and suggested it was the appropriate time to do so, they did not accept GCE as an achievable teaching opportunity that schools could provide. Participants agreed that being global was a status tied to capital resources. Making contact with foreigners, studying or travelling abroad, hosting educators from other countries and even purchasing foreign products were identified as evidence of being global. Participants stated that these experiences were not usual for a large proportion of their students considering that many of them were from low socioeconomic status (SES) families.

...they were trapped by their social niches; they were not able to get in touch with things beyond their environment. Their friends were also in similar situations. They always behave indifferently when you teach them about the dreams, the country or the associated responsibilities. (Teacher $\mathrm{H}, \mathrm{CY}$ )

It was also noted that a lack of support from parents and communities has prevented schools from needing GCE to promote heterogeneity in identity building. The importance of parental involvement was associated with the initiation of interest in studying GCE, helping with transport for conducting field studies for project-based learning, as well as learning resources they provide for their children, such as teaching them how to collect data from appropriate informative websites. Examples of teachers' comments are provided below.

So even if there was no such teaching content in the current formal curriculum, most students are able to cope with the activities in the society through selflearning during after-school hours. (Teacher J, CW). 
[When I supervised student projects] I took them out during self-study classes. I had to invite parents to go with me [to the Red Cross] because my car could not seat 16 students. The students had to take turns, with eight of them going out of school with me and a parent for the investigation one day and the other eight another day. (Teacher L, CZ).

In an ideal scenario, such as Teacher L's experience when conducting a project on investigating the Red Cross with students in CZ secondary school with support from parents and communities, an effective GCE curriculum could be developed. However, collaboration with parents and communities was not going smoothly. There was general concern from principals and teachers when working with parents regarding their lack of the necessary knowledge and skills. As for community support, participants reflected the hardship when community resources remained insufficient. Furthermore, according to Principal B, who managed HY secondary school, it was still the local education bureau who led reforms of immersing schools and communities, although occasionally, communities might be proactive in proposing activities related to GCE. Stronger home-school collaboration in GCE would take longer to develop in the schools participating in the present research.

In addition to issues related to "cultural and social changes and expectations', the emphasis on social mobility was associated with the conditions pupils brought to school. The household system in China, which used to immobilise residents, has had less impact on people's choices of where to send children to school since the opening up policy was introduced at the end of the 1970s. Migrant workers from less developed regions started to seek opportunities in cities. Among the secondary schools that participated in the project, all the public schools (i.e. except $\mathrm{CW}$ ) had many students from migrant workers' families. In CZ secondary school, half of the new students were from migrant workers' families; in QY secondary school, they constituted 60\% of the total student population; and in HY and FL secondary schools, the percentage was as high as $70 \%$. According to participants, these students' parents and guardians originated from various parts of the country. They brought with them different lifestyles, languages and values from their cultural regions. The participating schools not only have the traditional educational role of ensuring enrolment and transition rates and the social responsibility role of preparing students from low SES households for local job markets, but also the related ethical role of the teaching profession to empower students to be the type of citizens they are expected to develop.

We all know that China is going through a social transformation. At this stage, dozens of millions of migrant workers were travelling across the country, just like migratory birds. Their offspring follow them to this city and come to my school, constituting $70 \%$ of the student population. These migrant workers are, in Dostoevsky's words, the Humiliated and Insulted. They are living at the foot of the social ladder. Their children are growing up in an environment where their family education, their primary school education, their peers and the ideas they learn [are poor and limited]. Therefore, you do not have the right to complain in this school. (Principal Y, CY).

CY secondary school was not alone in facing this distressing situation as other public schools (i.e. CZ, HY, QY and FL) had similar issues; conversely, $\mathrm{CW}$, the only private school in the present research, was not affected by pupils' specific conditions.

The school norms also supported the social mobility theme. Normalised as self-sufficient institutions, participating schools received little support from civil society to organise educational activities. The self-sufficient way of operating schools resulted from not only the hierarchical management, but also the intentional isolation of schools from other societal sectors. On one hand, stakeholders outside schools disregarded their impacts on education. Both the principals and the teachers interviewed criticised parents and the community for not being responsible for education.

... the society should not only demand contributions

from education for its own sake, but also give back to education. (Principal U, QY)

On the other hand, the principals and teachers only mentioned wanting the community to be a provider of resources; they did not expect outsiders to intervene in their decisionmaking regarding the school curriculum. It seems plausible that communities and other societal sectors do not regard supporting education as part of their responsibilities. Nevertheless, due to efforts of the local educational bureaux, some schools were running volunteering programmes with charities and NGOs.

Finally, the material resources that contribute to the isolated status quo of schools relied heavily on outsourced teaching content for planning the non-national curriculum. Teachers mainly relied on national textbooks, which were the main first-hand materials they had access to at the same time as the de facto curriculum, the materials that dictated the teaching content in their classrooms. In contrast, the conditions that the principals and teachers expected for supporting curricula or activities such as GCE are not yet ready. Under such circumstances, educators were inclined to use well-developed programme packages as teachers were less likely to develop curriculum packages by themselves, although in some participating schools there have been attempts to design optional units for the school-based 
curriculum. Such curriculum packages have been offered by NGOs, enterprises, educational charities or foundations, all of which are introduced and managed by the local educational bureau, as otherwise the educational resource would not be recognised as official by the schools.

\section{Administrative constraints}

In the present research, participants identified administrative constraints as a factor limiting the implementation of more GCE in their schools. In general, the constraints centred on the unified workloads and the influence of leadership in schools.

As reflected in the management rigidity and formalisation in participating schools, a master plan with detailed regulations regarding workloads and schedule was disseminated by the local educational bureau as a strategy for achieving unification of workloads. In participating schools, participants generally reflected similar barriers that predisposed schools to the need for GCE to preserve heterogeneity. It was also noted that completing tasks assigned by higher officials was overly labour-intensive. This was a common concern in all the participating schools, especially for graduate teachers who were taking on multiple roles as subject teachers, class headteachers, elective unit teachers, and supervisors for project-based learning. Consequently, principals and teachers interpreted GCE as a challenge outside their job descriptions and an additional burden if addressed.

My time and energy are very, very limited. Most of the time, the will is there but not the strength [regarding any other worthwhile preparation for teaching]. (Teacher W, QY).

Although power over planning the curriculum in the Chinese education system should be in accordance with the hierarchical administrative arrangement, in a descending order from national to provincial to principals to teachers, the present study found that teachers could participate in developing the school-based curriculum in small or mediumsized schools, and this was more likely to occur when the principals were practising a progressive leadership style.

Despite the common characteristics and problems, there is variation in how GCE was perceived as a need among the participating schools. As revealed by the present study, the centralised education system in China means that most public schools are not distinguished from other school types. Consequently, school principals' leadership styles, underpinned by their moral beliefs and epistemology of using power, might be more important than the school type. In addition to the differences due to different leadership styles, the variation among schools is dependent on the school size. As highlighted regarding power distribution, in the huge private school, the administration operates in a more bureaucratic manner than the administration in the small or medium-sized community schools.

\section{Competency-based education}

Regardless of the constraints, competency-based education, which was one of the adjustments sought by participating schools to replace the assessment-dominated teaching convention, might help to overcome the difficulty in developing GCE. Although it was mentioned by participants either as a fixed term or as a concept shared by participants, there was no consensus on the meaning of competency-based education in this research. Despite the ambiguity, this concern was raised when participants mentioned elements that have been classified as themes in educational system requirements and challenges and the changing nature of the content, which are both external factors. More importantly, most participants associate the meaning of competency-based education with GCE.

As demonstrated in two sections reflecting problematic education contexts (Table 4), the revealed themes were the demand for quality of education and criticisms of the traditional score-based education system. Participants emphasised the dominant goal of improving students' examination scores. For instance, the term 'school's life-and-death benchmark' [Teacher F, FL] was used by a participant to describe the important role played by scores in the education system. The participant highlighted that such score-based education would not necessarily lead to the development of students' competencies, such as civic awareness and democratic participation.

The suggested competencies, echoing the call for ensuring the quality of education, originated from participants' evaluation of using a new version of Moral Education textbooks, which were supposed to be used across the country. For a decade, an old regional version of the textbook was used (across several provinces) for this subject; however, in 2016, a new provincial version of the textbook (only for use in Jiangsu province) compiled by local educators and researchers was introduced. One year later, a mandatory national version of the textbook, probably the primary source for GCE that teachers had to use based upon education system requirements, was introduced across the country. In the new national textbook, the structure, contents and learning objectives of the subject have changed, which participants believed were more aligned with enhancing students' general competencies. As described by the teachers in FL secondary school, the national textbooks dispensed with indoctrinating texts, such as paragraphs of conclusions and definitions, and now require teachers to ask students to actively listen and practise in class before they reach their own conclusions. Moreover, the new textbooks require two 
types of practical activities as the last teaching task of each unit. The principal from FL secondary school commented:

...the new textbooks substantiate students' learning of generative knowledge, which is brought into the overall knowledge framework by arranging scenario learning activities as part of teaching tasks... To meet the principles of Moral Education, there are more requirements around cultivating civic awareness from the perspectives of individuals, the individual and her classmates, and the individual and society... It is still unclear how to evaluate teaching from the new textbooks. We need to wait for the unified standards from the provincial education department and the provincial education research institute. (Principal Z, FL)

By summarising participants' feedback, it was found that the new textbooks might help to enhance students' learning experiences and cultivate their awareness of democratic participation. However, when the research was conducted, it was too early to identify any impact on GCE in the participating secondary schools.

In the interviews, by drawing upon state-of-the-art policies and teaching content, participants also indicated that achieving the competencies of civic awareness and democratic participation was consistent with the aim of competency-based education. All the principals and teachers mentioned the links between GCE and the national standards of student development (the acknowledged form of competency-based education). The standard referred to most commonly was 'Core Competencies and Values for Chinese Students' Development' (Core Competencies Research Group 2016).

...citizen literacy could be regarded as the main component of the core competencies and values for Chinese students' development, and it does not conflict with global citizenship education. (Principal B, HY)

Moreover, participants attached importance to the informal curriculum. In other words, the competency-based education based on the informal curriculum provides an opportunity to anchor GCE in participating schools, albeit on a less systematic basis than the formal curriculum.

\section{A narrow niche for integrating GCE}

The study found that for participating schools, the overall condition of rare perceived need and problematic implementation of GCE was revealed, contributing to a narrow niche for their education to integrate GCE effectively. This was manifest through four conditions, namely compliance and commitment, social mobility, administrative constraints, and competency-based education.
First, the major condition Chinese secondary schools encounter, in general, is consistent with the description of the difficult setting by UNESCO (2015), where specific learning materials were lacking, and schools were operating with an overcrowded curriculum. In addition, as teachers had not received specific training, they had to develop GCE content and skills themselves, which led to a problematic condition, especially given that there was a lack of resources and time. This is different from the situation in other countries, including Australia, the United Kingdom and South Korea, where the political rhetoric on GCE is manifest. Without emphasis on a policy for developing GCE, concerning compliance and commitment, participating schools are more likely to be occupied with compulsory tasks with a tendency to emphasise ethnic identity. Moreover, the phenomenon that GCE only exists in the extracurricular activities and is isolated from the formal curriculum is similar to the reported situation in South Korea, where GCE was marginalised due to the neoliberal hegemonies and inequality (Cho and Mosselson 2018). It also seems that GCE in this study will be a part of the extracurricular activities.

Second, the participating schools were more concerned about their overwhelming social role of converting migrant students into new citizens of the city. A social mobility schooling model was adopted that perceived students as a homogeneously disadvantaged group who performed poorly in an education system heavily reliant on scorebased examinations for evaluation and decision-making. The way participating schools perceive their students and their education echoes some cases in non-Western countries, for example, South Korea, a country also heavily influenced by the Confucian collectivist cultural heritage (Cho and Mosselson 2018); the Ghanaian case of an elite school, which is continuously affected by the colonial ideology (Howard et al. 2018); and Japan and the United Kingdom, where GCE is primarily used to improve employability (Hammond and Keating 2018). Teachers' focus on being competent in economic globalisation concurs with the finding of research conducted by Goren and Yemini (2016) that teachers regarded GCE as the education for students with high SES. Moreover, participants' perception of a Chinese social mobility model is different from that of some other countries. In European countries where the composition of students is more heterogeneous, including students from different countries, cultural backgrounds and ethnic groups, there is less advocacy for homogeneity (Tarozzi and Torres 2016) and increasingly more for multiculturalism (Print and Lange 2013). The present study found that students in participating schools who might belong to different ethnic groups or have different social backgrounds were being labelled as students who moved from other parts of the country to the investigated city (as opposed to the students who were local 
residents in the investigated city). Furthermore, because of the emphasis on examination-based evaluation, which is the dominant factor to measure students' readiness to enter the local job market, each school will remain a selfsufficient unit rather than collaborating with other groups in the local community. Consequently, this will prevent GCE from achieving maximal effects when students' civil life is neglected. This finding indicates that the learning conditions provided by these participating schools cannot satisfy the demand for good citizenship education, where a certain degree of heterogeneity of engagement not only in schools, but also with families, communities and other social sectors is needed (Geboers et al. 2013).

Third, regarding the administrative constraints, the related factors simply increase the difficulty for schools to integrate GCE at a more advanced level. These constraints are specific to the Chinese context, probably due to the communist administrative management, where there is strict top-down control from the statutory laws and regulations as well as from the internal governance realised by informal but binding documents, including normative documents and the top leader's speech (Wu 1995).

Finally, the requirement for competency-based education may underpin GCE, though in a less obvious way. Most competencies participants wish to develop in their students are those required to settle in the city rather than those required for reacting in a context beyond local communities. In this study, the city from which the sample schools were drawn is identified as progressing towards being more engaged with the international society, and therefore the effect of centring on the issue of competencybased education is subtle. In the literature, the less international regions, including the conflict-ridden areas such as South Sudan and Liberia, have even more severe issues in the development of GCE (Reilly and Niens 2014; Skårås et al. 2019).

Based on these four concerns, it is theorised that the Chinese secondary school education reflected in this study is a narrow niche for integrating GCE. This niche has been carved out by the schools themselves and the momentum remains with them. Despite being at the bottom of a highly centralised education system, the social systems that participating schools represent, which are vulnerable to challenges from both within and outside the systems themselves, have taken precedence over determining the need for GCE. This situation has not been fully addressed in the existing literature. In particular, GCE has previously been overstated generally as a strategy for mitigating local and global conflicts (Banks 2008; McKinney 2008; Niens and Reilly 2012; Reynolds 2015; Ruyter and Spiecker 2008), but considered less in terms of schools' own strategies for adjusting to the changing internal and external conditions, as in the case of the Chinese secondary schools in this research.

\section{Conclusion, implications and direction for future research}

To summarise, the participating schools expressed concerns about the need for GCE, mainly due to efforts by the schools themselves devoted to competency-based education. This was a result of coping with the increased demand for providing the type of education outlined in a new version of textbooks and policy statements as well as teachers' own attempts to deliver GCE knowledge and skills via programmes supported by NGOs despite restrictions from the administration, the major schooling purpose, and insufficient support and resources underpinning the good citizenship education. In other words, the integration of GCE in participating schools is conditioned by a narrow niche for change. The present study's findings support the literature on the dynamics of curriculum change outlined by Print (1993), who suggests that a curriculum change could emerge under societal change. In the present study, the conditions for developing competency-based education concur with the desired need for GCE within some schools (i.e. degrees of preserving heterogeneity in building the legitimising identity).

The findings of the study confirm the importance of contextual specificities in introducing educational innovations, as discussed by Riley (2004). On one hand, reforming from the bottom-up largely relies on the degree of compatibility with the context, in terms of both external factors (e.g. social and cultural ideologies) and internal factors (e.g. convincing different interest groups within schools), to allow spontaneous change to take place in schools (Riley 2004). Interrelated efforts from principals, teachers, community workers and parents have contributed to the momentum of popularising GCE within secondary schools similar to this selected Chinese case. On the other hand, it has been shown that the process of bottom-up reform, in contrast to other approaches to reform, requires phasing strategies (Riley 2004) and may be slow because of factors such as administrative constraints.

Chinese secondary schools in places like the city in this study need GCE in a way that is different from other contexts. The subtle yet smooth patterns of the popularisation of GCE among the participating schools seem to support this, which contrasts with practices in countries where some elements of GCE are well developed (e.g. multicultural education and intercultural education in North America, the Anglo-Saxon region and Northern Europe [Tarozzi and Torres 2016]). Moreover, the uniqueness of the Chinese case is manifest because of its administrative constraints, leading school personnel to rarely acknowledge the importance of preserving heterogeneity (a signal of the need for GCE), including both the heterogeneity 
in tolerating students' identities and the heterogeneity in involving agents in shaping the learning conditions (Geboers et al. 2013). Furthermore, since the selected Chinese case represents the situation in a less international region of China, it reveals features in two different types of regions. On one hand, findings indicate the similarity between this Chinese case and the Korean case in the ways they suffer from the neoliberal hegemonies and inequality (Cho and Mosselson 2018). On the other hand, barriers highlighted in this case, such as insufficient resources and lack of professional training, are consistent with those in conflict-ridden contexts (Goren and Yemini 2016; Skårås et al. 2019).

Finally, the limitations of the present study may be the small sample size and choosing samples from the east coast of China. It will be worth investigating whether the emerging yet complicated characteristics of GCE are comparable with those of secondary schools in other moderately developed regions, as the sample in this study was from one city. Moreover, as it was not covered in this exploratory research, it will be especially valuable to address to what extent the four key concerns that emerged in the present study would cause differences in changing to integrate GCE, for example, by conducting a large-scale survey in multiple Chinese cities.

Acknowledgement I thank Professor Murray Print for his valuable comments and suggested changes to the draft. I thank Dr Frank Reichert for helping examine the revised manuscript. Also, I thank Dr Rosaria Indah for her advice on writing the cover letter. Finally, I wish to thank Neriman Coskun for her genuine support during the lockdown.

Funding No sources of funding supported the study.

Availability of data and material The author confirms that the data supporting the findings of this study are available within the article.Code availability The researcher used NVivo (version11) for this piece of study, which complied with the field standards.

\section{Compliance with ethical standards}

Conflict of interest No financial or non-financial interests related the study.

Human ethics Human Ethics have been permitted by the committee located within the University of Sydney. The researcher obtained consent from participants in the study. Other procedures related to the human participants also followed the requirements of the Human Ethics.

\section{Appendix 1: Instruments for semi-structured interviews}

\section{School principals.}

What non-national curricular courses and activities does the school have?

- Moral Education/International Understanding Education/ Civics and Citizenship Education?

- Other school-based courses or activities?

What qualities does the school wish graduates to achieve through those courses and activities?

- Knowledge, skills and qualities/characteristics?

- What other aspects do you think that current students need to improve?

To what extent were those courses and activities related to GCE in terms of preparing students for the globalised society?

- What was your conception of GCE?

If there was an opportunity to implement a specific course or activity on GCE, how would you plan, develop and implement it?

- How will you develop by considering the school's advantages and disadvantages?

- What teachers will you invite to participate in GCE-related curriculum development?

\section{Teachers.}

What is your educational background, work experience and current role in school?

What knowledge, skills and qualities you wish to see in your school's graduates?

- Which of those do you think are more important?

- Through what standards will you judge your students?

Regarding GCE, how will you conceptualise it?

What content and format will you cover in GCE?

- Examples of (1) etiquette when travelling abroad, (2) angry youth, (3) smog, (4) Mekong River?

- How will you teach these things to students? 


\section{References}

Abdi, A. A. (2008). Educating for human rights and global citizenship. New York: SUNY Press.

Andreotti, V. (2006). Soft versus critical global citizenship education. Policy and Practice: A Development Education Review, 3, 83-98.

Bamber, P., Bullivant, A., Clark, A., \& Lundie, D. (2018). Educating Global Britain: Perils and possibilities promoting 'national'values through critical global citizenship education. British Journal of Educational Studies, 66(4), 433-453.

Banks, J. A. (2008). Diversity, group identity, and citizenship education in a global age. Educational Researcher, 37(3), 129-139. https://doi.org/10.3102/0013189X08317501.

Braun, K. (2019). Unpacking post-truth. Critical Policy Studies, 13(4), 432-436.

Buchanan, J., Burridge, N., \& Chodkiewicz, A. (2018). Maintaining global citizenship education in schools: A challenge for Australian educators and schools. Australian Journal of Teacher Education, 43(4), 51-67.

Castells, M. (2004). The power of identity (2nd ed.). Oxford: Blackwell.

Charmaz, K. (2006). Constructing grounded theory: A practical guide through qualitative analysis. California: Sage.

Charmaz, K. (2011). Grounded theory methods in social justice research. The Sage Handbook of Qualitative Research, 4(1), $359-380$

Chen, Y. G. (2014). Becoming global citizens through Bilingualism: Chinese citizenship education in a globalising world. In K. J. Kennedy, G. P. Fairbrother, \& Z. Z. Zhou (Eds.), Citizenship education in china: Preparing citizens for the "Chinese century" (pp. 129-144). New York: Routledge.

Cho, H. S., \& Mosselson, J. (2018). Neoliberal practices amidst social justice orientations: Global citizenship education in South Korea. Compare: A Journal of Comparative and International Education, 48(6), 861-878.

Core Competencies Research Group. (2016). Core competencies and values for Chinese students. Journal of The Chinese Society of Education., 10, 1-3.

Davies, L. (2006). Global citizenship: Abstraction or framework for action? Educational Review, 58(1), 5-25. https://doi. org/10.1080/00131910500352523.

Dill, J. S. (2013). The longings and limits of global citizenship education: The moral pedagogy of schooling in a cosmopolitan age. London, UK: Routledge.

England, K., \& Ward, K. (2007). Neoliberalization : states, networks, peoples. Oxford: Blackwell.

Featherstone, M. (2002). Cosmopolis: An introduction. Theory, Culture \& Society, 19(1-2), 1-16.

Gaudelli, W. (2009). Heuristics of global citizenship discourses towards curriculum enhancement. Journal of Curriculum Theorizing, 25(1), 68-85.

Geboers, E., Geijsel, F., Admiraal, W., \& Dam, G. (2013). Review of the effects of citizenship education. Educational Research Review, 9(2013), 158-173.

Goren, H., \& Yemini, M. (2016). Global citizenship education in context: Teacher perceptions at an international school and a local Israeli school. Compare: A Journal of Comparative and International Education, 46(5), 832-853. https://doi.org/10.1080/03057 925.2015.1111752.

Gow, M. (2017). The core socialist values of the Chinese dream: Towards a Chinese integral state. Critical Asian Studies, 49(1), 92-116. https://doi.org/10.1080/14672715.2016.1263803.

Hammond, C. D., \& Keating, A. (2018). Global citizens or global workers? Comparing university programmes for global citizenship education in Japan and the UK. Compare: A Journal of Comparative and International Education, 48(6), 915-934.

Hicks, D., \& Townley, C. (1982). Teaching world studies: An introduction to global perspectives in the curriculum. New York: Longman.

Ho, L. C. (2009). Global multicultural citizenship education: A Singapore experience. The Social Studies, 100(6), 285-293.

Hong, Y. (2019). Becoming global: Global Citizenship Education in Chinese middle schools in a second-tier city. Unpublished doctoral thesis. Australia: University of Sydney.

Howard, A., Dickert, P., Owusu, G., \& Riley, D. (2018). In service of the western World: Global citizenship education within a Ghanaian elite context. British Journal of Educational Studies, 66(4), 497-514.

Hyman, H. (1959). Political socialization. Glencoe, IL: Free Press.

iiMedia Research (2019). iiMedia Report: Analysis of inboard and outboard tourism industry and profiling customers. Retrieved from https://www.iimedia.cn/c400/63384.html

Jennings, M. K. (2007). Political socialization. In R. J. Dalton \& H. Klingemann (Eds.), The Oxford handbook of political behavior (pp. 29-44). Oxford: Oxford University Press.

Johnson, L., \& Morris, P. (2010). Towards a framework for critical citizenship education. Curriculum Journal, 21(1), 77-96.

Kennedy, K. J. (2014). “The 'citizenship industry' and students identities: is there an alternative to state-focused citizenship education?", Keynote Address, 16th Children's Identity and Citizenship in Europe Network Conference, Innovative Practice and Research Trends in Identity, Citizenship and Education, University of Warmia and Mazury, Olsztyn, 12-14 June.

Kharas, H. (2011). The emerging middle class in developing countries $(P P T)$. Washington: Brookings Institution.

Koh, A. (2007). Deparochializing education: Globalization, regionalization, and the formation of an ASEAN education space. Discourse studies in the cultural politics of education, 28(2), 179195. https://doi.org/10.1080/01596300701289144.

Labaree, D. F. (1999). How to succeed in schools without really learning: The credential race in American education. New Haven, CT: Yale University Press.

Law, W. W. (2002). Education Reform in Taiwan: A search for a 'national' identity through democratisation and Taiwanisation. Compare: A Journal of Comparative and International Education, 32(1), 61-81. https://doi.org/10.1080/03057920120116535.

Law, W. W. (2006). Citizenship, citizenship education, and the state in China in a global age. Cambridge Journal of Education, 36(4), 597-628.

Law, W. W. (2013). Globalization, national identity, and citizenship education: China's search for modernization and a modern Chinese Citizenry. Frontier Education in China, 8(4), 596-627.

Law, W. W. (2014). Globalisation, citizenship education, and international events: 2010 Shanghai World Exposition Education in China. In K. J. Kennedy, G. P. Fairbrother, \& Z. Z. Zhou (Eds.), Citizenship education in china: Preparing citizens for the "Chinese century" (pp. 100-127). New York: Routledge. https://doi. org/10.4324/9780203797129.

Lee, W. O., \& Leung, S. W. (2006). Global citizenship education in Hong Kong and Shanghai secondary schools: Ideals, realities and expectations. Citizenship Teaching and Learning, 2(2), 68-84.

Li, T. P. (2003). The political education in the process of globalization. Journal of Nanjing Normal University (Social Science), 1(2003), $56-60$.

Li, Y. J. (2009). Developing global citizen: A new trend in citizenship education. Teacher in China, 2009(94), 30-32.

Lingam, G. I., Burnett, G., Lilo, J. F., \& Lingam, N. (2014). Curriculum reform in Solomon Islands: A shift from Eurocentrism to Solcentrism in curriculum making. Asia-Pacific Edu Res, 23(3), 345-353. 
Macbeath, J. (2004). Democratic learning and school effectiveness: are they by any chance related? In J. MacBeath \& L. Moos (Eds.), Democratic learning: the challenge to school effectiveness (pp. 19-51). London: Routledge Farmer. https://doi.org/10.4324/97802 03352908 .

McKinney, S. J. (2008). Immigrants and religious conflict: Insider accounts of Italian, Lithuanian, and Polish Catholics in Scotland. In M. Peters, A. Britton, \& H. Blee (Eds.), Global citizenship education: Philosophy, theory, and pedagogy (pp. 333-349). Rotterdam: Sense.

Ministry of Education. (2011). Compulsory education curriculum standards of moral education. Beijing: People's Education Press. Retrieved from https://old.pep.com.cn/sxpd/js/tbjx/kb/kcbz/20120 3/t20120312_1107258.htm

National Bureau of Statistics of China (2019). Education: Statistics of postgraduates (recruitment, at school, and graduates); Chinese students studying aboard; returned overseas students. Retrieved from https://data.stats.gov.cn/easyquery.htm? $\mathrm{cn}=\mathrm{C} 01 \& \mathrm{zb}=\mathrm{A} 0 \mathrm{~K} 05$ $\& s j=2018$

Newman, W. L. (2014). Social research methods: Qualitative and quantitative approaches (7th ed.). England: Pearson Education.

Niens, U., \& Reilly, J. (2012). Education for global citizenship in a divided society? Young people's views and experiences. Comparative Education, 48(1), 103-118.

Nussbaum, M. (2002). Education for citizenship in an era of global connection. Studies in Philosophy and Education, 21(4-5), 289-303.

Oxfam (2015) Education for global citizenship: A guide for schools. Retrieved from https://www.oxfam.org.uk/education/resources/ education-for-global-citizenship-a-guide-for-schools

Oxley, L., \& Morris, P. (2013). Global citizenship: A typology for distinguishing its multiple conceptions. British Journal of Educational Studies, 61(3), 301-325.

Pan, S. Y. (2014). Multileveled citizenship education in Beijing: Liberation with limitation. In K. J. Kennedy, G. P. Fairbrother, \& Z. Z. Zhou (Eds.), Citizenship education in China: Preparing citizens for the "Chinese century". New York: Routledge.

Peng, J. (2009). Discussion about cosmopolite cultivation by China's colleges. Journal of Sichuan Normal University (Social Science Edition), 36(3), 54-59.

Podoshen, J. S., Li, L., \& Zhang, J. (2011). Materialism and conspicuous consumption in China: A cross-cultural examination. International journal of consumer studies, 35(1), 17-25.

Print, M. (1993). Curriculum development and design (2nd ed.). St Leonards, NSW: Allen \& Unwin.

Print, M. (2007). Citizenship education and youth participation in democracy. British Journal of Educational Studies, 55(3), 325345. https://doi.org/10.1111/j.1467-8527.2007.00382.x.

Print, M. (2013). Competences for democratic citizenship in education. In M. Print \& D. Lange (Eds.), Civic education and competences for engaging citizens in democracies (pp. 37-50). Rotterdam: Sage.

Print, M. (2015). The "Good" Citizen for the 21st century: A curriculum perspective. In M. Print \& C. B. Tan (Eds.), Educating "Good" citizens in a globalising world for the twenty-first century (pp. 33-48). Rotterdam, The Netherlands: Sense Publishers.

Print, M., \& Buchanan, J. (2019). "And Its Ghost May Be Heard": Policy and practice in civics and citizenship education in Australia over two decades. In J. Pineda-Alfonso, N. De Alba-Fernández, \& E. Navarro-Medina (Eds.), Handbook of research on education for participative citizenship and global prosperity (pp. 89-107). Hersey, PA: IGI Global.

Print, M., \& Coleman, D. (2003). Towards understanding social capital and citizenship education. Cambridge Journal of Education, 33(1), 123-149.
Print, M., \& Lange, D. (2013). Civic education and competences for engaging citizens in democracies (Vol. 3). Berlin: Springer. https ://doi.org/10.1007/978-94-6209-172-6.

Reilly, J., \& Niens, U. (2014). Global citizenship as education for peacebuilding in a divided society: Structural and contextual constraints on the development of critical dialogic discourse in schools. Compare: A Journal of Comparative and International Education, 44(1), 53-76.

Reynolds, R. (2015). One size fits all? Global education for different educational audiences. In R. Reynolds, et al. (Eds.), Contesting and constructing international perspectives in global education (pp. 27-41). Rotterdam, The Netherlands: Sense Publishers.

Riley, K. (2004). Reforming for democratic schooling: Learning for the future nor yearning for the past. In J. MacBeath \& L. Moos (Eds.), Democratic learning: The challenge to school effectiveness (pp. 52-73). London: Routledge. https://doi. org/10.4324/9780203352908.

Ruyter, D., \& Spiecker, B. (2008). The world citizen travels with a different view. In M. A. Peters, A. Britton, \& H. Blee (Eds.), Global citizenship education (pp. 351-363). Leiden: Brill Sense.

Settle, J. E., Bond, R., \& Levitt, J. (2011). The social origins of adult political behavior. American Politics Research, 39(2), 239-263.

Shi, Y., Chong, E., \& Li, B. (2019). Chinese civic education being globalised. Social Transformations in Chinese Societies, 15(1), 37-63. https://doi.org/10.1108/STICS-11-2018-0016.

Skårås, M., Carsillo, T., \& Breidlid, A. (2019). The ethnic/local, the national and the global: Global citizenship education in south sudan. British Journal of Educational Studies. https:// doi.org/10.1080/00071005.2019.1598540.

Song, Q., \& Rao, C. M. (2018). Focus on global common good: The new international research trend on world citizenship education. Modern Educational Management, 2018(2), 106-111.

Tarozzi, M., \& Torres, C. A. (2016). Global citizenship education and the crises of multiculturalism: Comparative perspectives. London, UK: Bloomsbury Publishing.

Teasdale, G. R. (1997). Globalisation, Localisation: Impacts and Implications for teacher education in the Asia-Pacific region. Paper presented at Annual Conference of the Australian Teacher Education Association (27th), Queensland, Australia.

Thaman, K. H. (2009). Towards cultural democracy in teaching and learning with specific references to Pacific Island Nations (PINs). International Journal for the Scholarship of Teaching and Learning, 3(2), 1-9.

Torney-Purta, J. (2002). The school's role in developing civic engagement: A study of adolescents in twenty-eight countries. Applied Developmental Science, 6(4), 203-212.

Torney-Purta, J., Richardson, W., \& Barber, C. (2004). Governmentrelated institutions and civic engagement among adolescents: Analysis of five countries from the IEA civic education study (CIRCLE Working Paper 17). Medford, MA: Center for Information and Research on Civic Learning and Engagement.

Tye, K. A. (2003). Global education as a worldwide movement. The Phi Delta Kappan, 85(2), 165-168. https://doi. org/10.1177/003172170308500212.

UNESCO (2015). Global citizenship education: Topics and learning objectives. Retrieved from https://en.unesco.org/news/globa 1-citizenship-education-topics-and-learning-objectives

UNESCO APCEIU (2019). United Nations educational, scientific and cultural organization Asia-Pacific Centre of Education for International Understanding. Retrieved from https://www.unrok.org/about-un/offices/unesco-apceiu/

UNESCO Courier. (2018). Welcome to the Anthropocene! Courier (Vol. 2). Paris: UNESCO Courier. 
Veugelers, W. (2007). Creating critical-democratic citizenship education: Empowering humanity and democracy in Dutch education. Compare, 37(1), 105-119.

Wang, C. (2016). Individuality, hierarchy, and dilemma: The making of confucian cultural citizenship in a contemporary Chinese classical school. Journal of Chinese Political Science, 21(4), 435-452. https://doi.org/10.1007/s11366-016-9436-9.

Wang, L. P. (2019). Possibility of global citizenship education in china: A secondary school curriculum perspective. UNES NUM, 2019(12), 127-143.

Westheimer, J., \& Kahne, J. (2004). What kind of citizen? The politics of educating for democracy. American Educational Research Journal, 41(2), 237-269.

Wu, G. (1995). "Documentary Politics": Hypotheses, process, and case studies. In C. L. Hamrin \& S. Zhao (Eds.), Decision-making in Deng's China perspectives from insiders (pp. 24-38). Armonk, N.Y: M.E. Sharpe.

Xu, W. X. (1998). An essay help you understand the National conditions. China National Conditions and Strengths., 4(1998), 33-34. https://doi.org/10.13561/j/cnki.zggqgl.1998.04.005.

Youniss, J., McLellan, J. A., \& Yates, M. (1997). What we know about engendering civic identity. American Behavioral Scientist, 40(5), 620-631.
Zhang, J. F. (2006). Some issues concerning the understanding of IPAC. Policies of IPAC. Retrieved from https://ipac.cersp.com/ LLDH/KCZC/200609/1053.html

Zhao, X., Selman, R. L., \& Haste, H. (2015). Academic stress in Chinese schools and a proposed preventive intervention program. Cogent Education, 2(1), 1000477.

Zhao, Z. Z. (2010). Conceptualization of citizenship education in the Chinese Mainland. Educational Journal, 37(1-2), 57-69.

Zheng, G. X. (2008). Dilemma of the integrated curriculum of practical activity and countermeasures. Research in Educational Development, 2(2008), 83-85. https://doi.org/10.14121/j.c nki.1008-3855.2008.02.021.

Zhou, P. Y. (2011). Localization of the global education. Resources for Research and Learning, 28(5), 5-15.

Publisher's Note Springer Nature remains neutral with regard to jurisdictional claims in published maps and institutional affiliations. 